ISSN 1112-9867

http://www.jfas.info

\title{
EVALUATION OF ANTIOXIDANT ACTIVITY AND POLYPHENOLIC CONTENTS OF TWO SOUTH ALGERIAN EGGPLANTS CULTIVARS
}

\author{
A. Djouadi*, T. Lanez and C. Boubekri \\ University of El Oued, VTRS Laboratory, PO Box 789, 39000, El Oued, Algeria
}

Received: 01 Nouvembre 2015 / Accepted: 18 Mars 2016 / Published online: 01 May 2016

\begin{abstract}
Polyphenolic compounds and antioxidant activity in eggplants (Solanum melongena L.) seem to depend on cultivar, maturity stage, environmental conditions and the part of the fruit. In this work, the polyphenolic content and antioxidant activity of pulp, whole fruit and peel from fresh dark-purple and white eggplant varieties cultivated in Southern Algeria were measured. Total phenolic content were determined by Folin-Ciocalteu test, and antioxidant activity measured using cyclic voltammetry. Correlations between antioxidant activity and total phenolic content were also examined. Within each cultivar, the total phenolic content and antioxidant activity were highest in the peels, followed by the whole fruit and the pulp. In the peel, whole fruit and pulp the dark-purple eggplant had the highest total phenolic contents and the highest total antioxidant activities.
\end{abstract}

Keywords: Solanum melongena L.; antioxidant capacity; total phenolic content; cyclic voltammetry.

Author Correspondence, e-mail: assia.lmd@gmail.com

doi: http://dx.doi.org/10.4314/jfas.v8i2.3 


\section{INTRODUCTION\#}

Eggplant (Solanum melongena L.) originating from Asia is one of the most widespread vegetables in the world [1], is consumed throughout the world and contains a variety of phytochemicals such as phenolics and flavonoids that provide important health benefits [2]. Phenolics show high biological activity [3-5]. They have antioxidant, antibacterial and immunostimulant properties. There is a big diversity of eggplant cultivars on the market varying in shape, size and color, the most common ones being dark purple or violet [1]. Eggplant fruit commonly known as aubergine, melanzana, garden egg, brinjal, or patlican is ranked amongst the top ten vegetables in terms of antioxidant capacity due to the fruit phenolic constituents [6]. The two varieties cultivated eggplant in Algeria; are dark purple and white and are widely used in cooking; their highest growing season is from November to January. As only a few information concerning the total phenolic contents and antioxidant activity of eggplant from Algeria can be found in literature [7], the present study aimed to:

$\checkmark$ Determine the phenolic content that exist in two south Algerian eggplants varieties,

$\checkmark$ Measure the in vitro antioxidant activities,

$\checkmark$ Determine correlations between antioxidant activities and total phenolic content.

\section{RESULTS AND DISCUSSION}

\subsection{Total phenolic content}

Polyphenols, the large group of phytochemicals, are known to act as antioxidants [11,12]. Table 1 shows the total phenolic content of different parts of two eggplant varieties (FDPE and FWE) from Algeria. The Total amounts of phenolics values of different parts extract ranged from $548.77 \mathrm{mg}$ to $15.29 \mathrm{mg} \mathrm{GA} / \mathrm{g}$ extract (see Table 1). 
Table 1. Total phenolic content (mg gallic acid equivalents/ $\mathrm{g}$ dry extract) of different parts of eggplant cultivars

\begin{tabular}{ccccccc}
\hline \multirow{2}{*}{ Cultivar } & \multicolumn{3}{c}{ EF } & \multicolumn{3}{c}{ AF } \\
\cline { 2 - 7 } & Whole fruit & Pulp & Peel & Whole fruit & Pulp & Peel \\
\hline FDPE & 20.14 & 24.13 & 548.77 & 19.47 & 23.78 & 82.31 \\
FWE & 30.51 & 25.29 & 87.82 & 15.43 & 15.29 & 41.30 \\
\hline
\end{tabular}

Eggplant peels in two fraction (EF and AF) possess higher contents of total phenolic compounds compared to pulp and whole fruit but the peel of FDPE cultivar showed significantly higher phenolic content as compared to the FWE. Among all different parts of two eggplant varieties studied, significant differences in total phenolic content were found in comparisons between FDPE and FWE, and significant differences from each other were found between $\mathrm{EF}$ and $\mathrm{AF}$.

In general, the phenolic content of different parts of ethanolic extracts decreased as follows: peel $>$ whole fruit $>$ pulp for FWE whereas decreased in the following order: peel $>$ pulp $>$ whole fruit for FDPE.

\subsection{Evaluation of antioxidant capacities}

In order to express the antioxidant capacity of different parts of the eggplant extracts in equivalent terms of ascorbic acid equivalent antioxidant capacity (AEAC), different concentrations of the standards ascorbic acid $(0.018$ to $0.190 \mathrm{~g} / \mathrm{L})$ were plotted verses the anodic current density obtained from different cyclic voltammograms at $\mathrm{pH} 7$ in $0.2 \mathrm{M}$ phosphate buffer solution as a supporting electrolyte using a $3 \mathrm{~mm}$-diameter glassy carbon electrode. The equation obtained from the linear calibration graph in the studied concentration range for ascorbic acid is, $\mathrm{y}=126.03 \mathrm{x}+1.929$ (where $\mathrm{y}$ represents the value of the anodic current density and $\mathrm{x}$, the value of standards concentration, expressed as $\mathrm{mg} / \mathrm{mL}$ ), with a correlation coefficient of $\mathrm{R}^{2}=0.998$.

The total antioxidant capacity was calculated based on the following equation (1),

$$
T A C=\frac{C_{1}}{C_{2}}
$$


Where TAC is total antioxidant capacity, $\mathrm{C}_{1}$ is the eggplant sample extract concentration $(\mathrm{mg} / \mathrm{mL})$ calculated by replacing the current density obtained from different voltammograms of sample extracts in the equation $y=126.03 x+1.929, C_{2}$ is the sample concentration in the electrochemical cell $(\mathrm{g} / \mathrm{mL})$.

Figure 1 and 2 show different voltammograms of different parts of dark purple and white eggplant, each voltammogram shows one oxidation peak and one reduction peak. This reversible electrochemical behavior may indicate that, under this electrochemical conditions, the ethanolic eggplant extract contain a different polyphenolic content of that of the standard ascorbic acid.
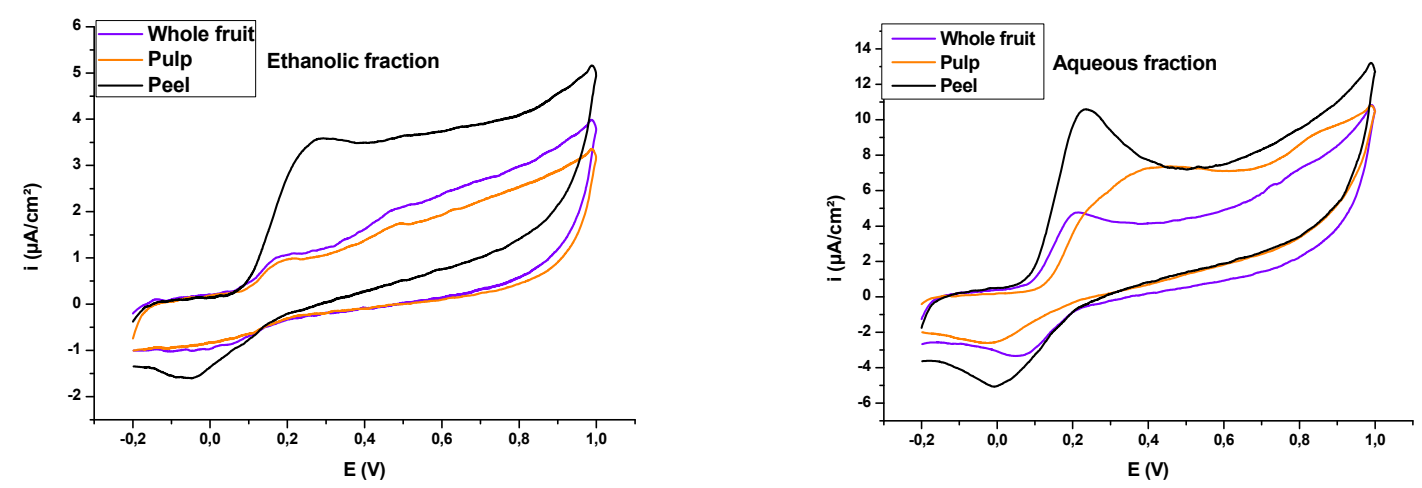

Fig.1. Cyclic voltammograms of different parts of fresh dark purple eggplant in pH 7, 0.2 M phosphate buffer solution at scan rate $100 \mathrm{mV} / \mathrm{s}$
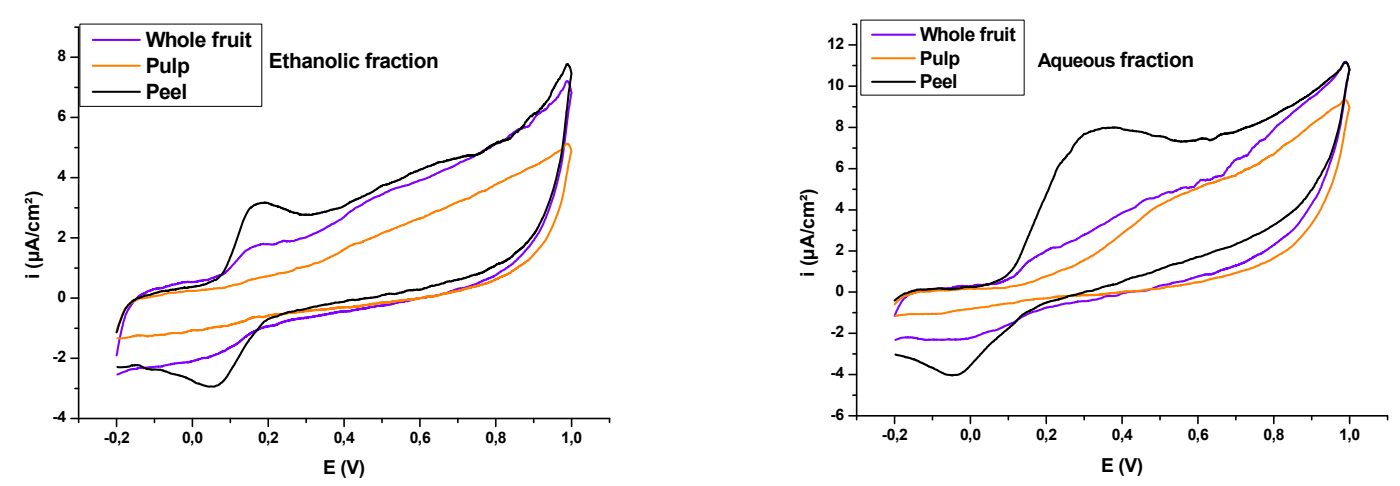

Fig.2. Cyclic voltammograms of different parts of fresh white eggplant in $\mathrm{pH}$ 7, 0.2 M phosphate buffer solution at scan rate $100 \mathrm{mV} / \mathrm{s}$ 
The total antioxidant capacity expressed as mg AA/g of dry extract of different parts of eggplant extracts calculated from the equation $y=126.03 x+1.929$ obtained from the calibration graphs for ascorbic acid is summarized in Table 2.

Table 2. Antioxidant capacities (mg ascorbic acid/g of dry extract) of different parts of the two different varieties of eggplant

\begin{tabular}{cccc}
\hline \multirow{2}{*}{ Variety } & parts & \multicolumn{2}{c}{ Ascorbic acid antioxidant capacities $(\mathrm{mg} / \mathrm{g})$} \\
\cline { 3 - 4 } & Whole fruit & 10.91 & AF \\
\hline \multirow{2}{*}{ FDPE } & Pulp & 11.83 & 8.50 \\
& Peel & 324.34 & 6.13 \\
& Whole fruit & 5.40 & 59.33 \\
& Pulp & - & 1.63 \\
FWE & Peel & 89.52 & 1.50 \\
& & & 17.50 \\
\hline
\end{tabular}

Like the total phenolic content, also the antioxidant activity varies considerably depending of the part of the fruit and of the eggplant cultivar analyzed. As it can be seen from table 2, the ethanolic fraction of peel extracts have the highest AEAC values of 324.34 and $89.52 \mathrm{mg} / \mathrm{g}$ for dark purple and white eggplant respectively, followed by pulp of dark purple variety and finally 10.91 and $5.40 \mathrm{mg} / \mathrm{g}$ for the whole fruit of dark purple and white variety respectively. However the pulp of white eggplant variety does not have any measurable antioxidant capacity using cyclic voltammetry techniques. On the other hand, the higher antioxidant values of eggplant peels is due to the presence of nasunin (delphinidin-3-p-coumaroylrutinoside-5-glucoside), the most common eggplant anthocyanin present in the dark purple of eggplant peels. The presence of which was first reported by Kuroda and Wada $[1,13]$. Also, it was shown that anthocyanins extracts from eggplant peel extracts exhibited higher antioxidant values [1]. The results of this study were consistent with a number of previous studies which state that eggplants possessed strong antioxidant capacity and that the value varied between eggplants parts and cultivars $[2,7,14]$. 
There was a significant positive correlation between total phenolic content and antioxidant activity and in pulp; whole fruit and peel (see Figure 3).
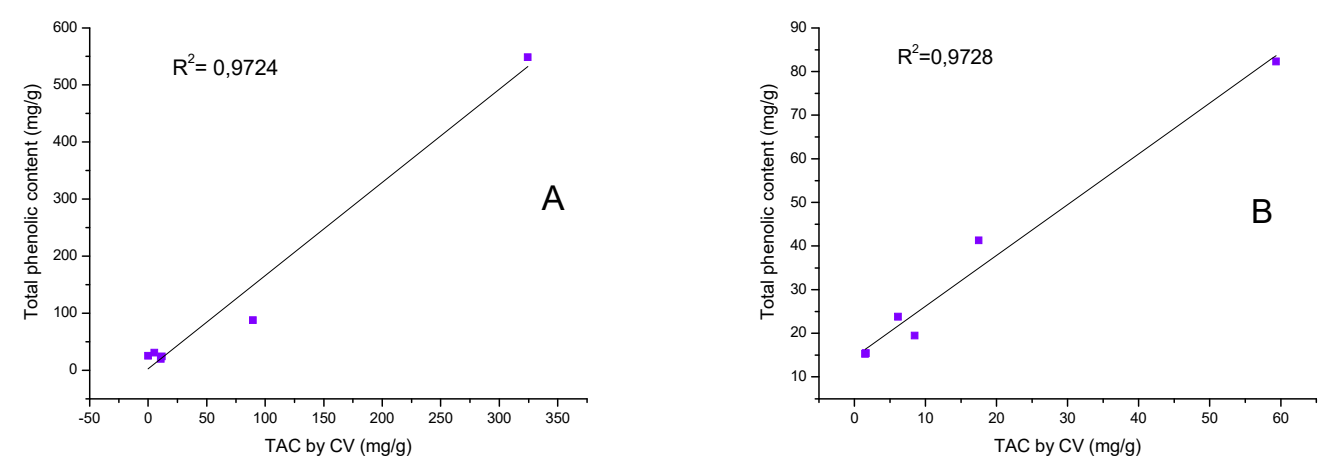

Fig.3. Correlation of total phenolic content and antioxidant capacity for extract from different parts of eggplant (A) ethanolic Fraction, (B) aqueous Fraction

\section{EXPERIMENTAL}

\subsection{Materials and methods\#}

\subsubsection{Chemical}

Ethanol (99\%), was purchased from Sigma-Aldrich Co. ascorbic acid (99.7\%), sodium carbonate (99\%), were both purchased from Merck Co. Folin-Ciocalteu reagent was purchased from biochem chemopharma Co (Canada). all other reagents used were of analytical grade.

\subsubsection{Plant material}

Dark purple and white eggplant fruits were purchased fresh from a local market in Guemar (El-Oued), Algeria in November 2011. After collection, the samples were analysed for phenolic contents and antioxidant evaluation.

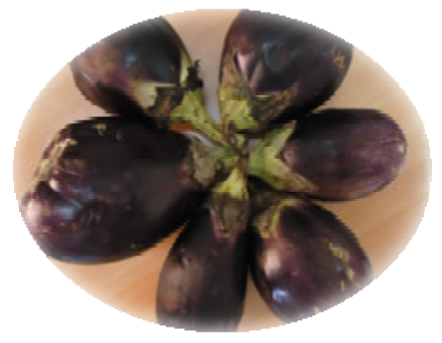

Fresh Dark Purple Eggplant (FDPE)

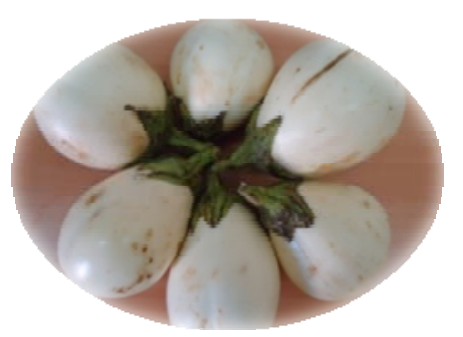

Fresh White Eggplant (FEW)

Fig.4. Two varieties of eggplant used in this study 


\subsubsection{Extraction of eggplant constituents}

Immediately after receipt of fresh eggplant, all eggplant samples was cleaned and peeled using a kitchen knife, and the pulp and the peel of the fruit were separated. Each part was chopped into small pieces. The fresh samples were then extracted with $130 \mathrm{~mL}$ of ethanol for 2 hours using Soxhlet apparatus. The samples were then filtered using Whatman filter $\mathrm{N}^{\mathrm{o}} .4$ paper; the filtrate was recovered and evaporated using a rotavapor at reduced temperature and pressure. After evaporation the residue was re-dissolved in ethanol and filtered (this consist the ethanolic fraction EF), the remaining insoluble materials were re-dissolved in water and filtered (this consist the aqueous fraction AF). All dry fractions were sealed in a glass flask and stored at low temperature until used.

\subsubsection{Total phenolic content}

The total phenolic contents of the eggplant samples were measured using a colorimetric Folin-Ciocalteu method [8]. $0.1 \mathrm{~mL}$ of the extract was diluted with ultrapure water to $1 \mathrm{~mL}$; $0.5 \mathrm{~mL}$ of Folin-Ciocalteu reagent diluted ten fold with ultrapure water was then added. After a period of 3 minutes, $2 \mathrm{ml}$ of saturated sodium carbonate solution was added. The mixture was incubated at room temperature for 30 minutes. The absorbance was measured against a blank at $760 \mathrm{~nm}$ using Shimadzu UV-Vis-1800 spectrophotometer. The measurement was compared to a standard curve of prepared gallic acid solutions (10 points from 3 to $300 \mathrm{mg} / \mathrm{L}$ ) and expressed as milligrams of gallic acid equivalents per gamme of dry extract.

\subsubsection{Evaluation of antioxidant capacity}

The measurement of the antioxidant capacity of the studied eggplant samples was performed using an electrochemical method based on cyclic voltammetry techniques. Cyclic voltammetry measurements were performed using PGP301 potentiostat (radiometer analytical SAS) connected to an electrochemical cell with a volumetric capacity of $50 \mathrm{~mL}$ containing a glassy carbon working electrode, a Pt wire counter electrode and an $\mathrm{Hg} / \mathrm{Hg}_{2} \mathrm{Cl}_{2}$ reference electrode. The potential was swept in direct scanning mode starting from -200 to $+1000 \mathrm{mV}$ with a scanning rate of $100 \mathrm{mV} / \mathrm{s}$. The antioxidant capacity was obtained using the current density of the anodic curve of the voltammogram. The calibration graph is obtained by plotting the current density of the anodic curve of the voltammogram of each sample of the 
standard versus its concentration. Ascorbic acid was used as a standard in the calculation of antioxidant capacity of the studied sample of eggplant because of its wide spreading in nature and also because its anodic current density displays excellent linearity toward ascorbic acid concentrations $[9,10]$.

In this study we investigated relations between fruit color, polyphenols, and antioxidant activities of two eggplant cultivars. The polyphenol content and antioxidant activities for the dark purple eggplant were different from that of the white eggplant cultivars .The fresh dark purple cultivar eggplant showed significantly higher phenolic content and antioxidant activity as compared to white. Considering the results for different parts of two cultivars studies, fresh peel of dark purple eggplant variety has the highest antioxidant capacity. The antioxidant activity of the two fresh cultivars correlated well with the total phenolic content.

\section{ACKNOWLEDGMENT}

Authors are grateful to Mr. Ali Tliba from Laboratoire de Valorisation et Technologie des Ressources Sahariennes (VTRS) staff and Mr. Abdelkarim Rebiai senior lecturer for their assistance in electrochemical and spectrophotometric analysis.

\section{REFERENCES}

[1] Sadilova E., Stintzing F.C., Carle R., Anthocyanins, colour and antioxidant properties of eggplant (Solanum melongena L.) and violet pepper (Capsicum annuum L.) peel extracts, Verlag der Zeitschrift für Naturforschung, Tübingen. 2006, 61 (7-8), 527-535.

[2] Akanitapichat P., Phraibung K., Nuchklang K., Prompitakkul S., Food Chem Toxicol. 48, 2010, 3017-3021, doi: 10.1016/j.fct.2010.07.045.

[3] Lattanzio V., Food Chem. 24, 1987, 37-50, doi: 10.1016/0308-8146(87)90082-3.

[4] Babic I., Amiot M. .J., Nguyen-the C., Acta Hortic. 343, 1993, 123-128, doi: 10.1111/j.1365-2621.1993.tb 04273.x.

[5] Leja M., Stodolak B., Mareczek A., Rożek S., Wojciechowska R., Effect of post-harvest storage on metabolism of phenol compounds in carrot root slices, Folia Hort. 9, 1997, $59-69$. 
[6] Cao G., Sofic E., Prior R. L. , J. Agric. Food Chem. 1996, 44 (11), 3426-3431, doi: 10.1021/jf9602535.

[7] Boubekri C, Rebiai A, Lanez T., Study of antioxidant capacity of different parts of two south algerian eggplant cultivars, J. Fundam. Appl. Sci. 4 (2), 2012, 16-25.

[8] Scalbert A, Monties B, Janin G., J. Agric. Food Chem. 1989, 37 (5), 1324-1329, doi: 10.1021/jf00089a026.

[9] Laskar R.A., Sk I., Roy N., Begum N.A., Food Chem. 2010, 122 (1), 233-237, doi:10.1016/j.foodchem.2010.02.068.

[10] Barros L., Falcao S., Baptista P., Freire C., Vilas-Boas M., Ferreira ICFR., Food Chem. 2008, 111(1), 61-66, doi:10.1016/j.foodchem.2008.03.033.

[11] Bors W., Michel C., Stettmaier K., Methods Enzymol. 335, 2001, 166-180, doi: 10.1016/S0076-6879(01)35241-2.

[12] Rice-Evans C., Miller N., Paganga G., Trends Plant Sci. 1997, 2 (4), 152-159, doi : http://dx.doi.org/10.1016/S1360-1385(97)01018-2.

[13] Mazza G. and Miniati E. Anthocyanins in fruits, vegetables, and grains. Boca Raton/FL., USA: CRC Press, 1993, pp. 301-305.

[14] Singh A.P., Luthria D., Wilson T., Vorsa N., Singh V., Banuelos G.S., Pasakdee S., Food Chem. 2009, 114 (3), 955-961, doi: 10.1016/j.foodchem.2008.10.048.

\section{How to cite this article:}

Djouadi A, Lanez T and Boubekri C. Evaluation of antioxidant activity and polyphenolic contents of two south Algerian eggplants cultivars. J. Fundam. Appl. Sci., 2016, 8(2), 223-231. 